\title{
sige \\ Paisajes aldeanos de la cuenca del río Anillaco, Castro Barros, La Rioja (ca.300-800 D.C.). Resultados preliminares
}

RMA

VI Jornadas

Arqueológicas Cuyanas

\author{
The village landscapes of the Anillaco River, Castro Barros, \\ La Rioja (ca.300-800 AD). Preliminary results
}

\author{
Gabriela Inés Sabatini* y Pedro Miguel Salminci (†)
}

${ }^{*}$ Centro Regional de Investigaciones Científicas y Transferencia La Rioja (CRILAR), Provincia de La Rioja, UNLAR, SEGEMAR, UNCa, CONICET, Entre Ríos y Mendoza s/n, (5301) Anillaco, La Rioja (Argentina). E-mail: gsabatini@crilar-conicet.gob.ar

\begin{abstract}
Resumen
Presentamos los resultados de un diseño de prospección de cobertura total del piedemonte de Anillaco, Castro Barros (La Rioja). Empleamos Sistemas de Información Geográfica (SIG) como herramienta espacial para identificar los paisajes aldeanos.

Nos focalizamos en las trayectorias temporales con el fin de comprender la dinámica ocupacional de las comunidades que habitaron el área entre 300 y 800 D.C.

Planteamos la configuración de dos diferentes momentos constructivos durante el período Formativo local, como reflejo de un uso continuo del espacio y de diferentes escalas sociales y económicas.
\end{abstract}

Palabras clave: paisaje; comunidad; Formativo; Sistemas de Información Geográfica.

\begin{abstract}
We present the results of a total full cover survey design of the Anillaco basin's foothills, Castro Barros (La Rioja). We employed spatial Geographical Information Systems (GIS) as tool to identify the village landscapes.

We focused in temporal trajectories in order to understand the occupational dynamics of communities that lived between in the area 300 and 800 A.D.

We propose the configuration of two different constructive moments during the local formative period, reflecting a continuous use of the space and different social and economic levels.
\end{abstract}

Keys words: landscape; community; Formative; Geographical Information Systems; spatial analysis.

En este trabajo se parte de una perspectiva de análisis espacial multiescala de los procesos sociales, teniendo en cuenta lo regional (Departamento de Castro Barros), microrregional que involucra la cuenca de Anillaco y finalmente el estudio de locaciones específicas como el conjunto arquitectónico Uchuquita 1, 2 y 3. Asimismo nos enfocamos en las trayectorias temporales con el fin de construir el paisaje social en la cuenca del río Anillaco entre 300 y 800 D.C.

Presentamos los resultados preliminares de prospección intensiva de Anillaco desde los faldeos de la Sierra de Velasco hasta la Sierra la Punta (Figura 1). La información relevada nos permitió identificar no sólo las diferentes locaciones arqueológicas (áreas de cultivo, molienda y residencial) sino también distinguir dos capas temporales: un primer componente (300-600 D.C) y un segundo componente (600-800 D.C).

Por último, realizamos relevamientos planimétricos, intervenciones de excavación y fechado radiocarbónico de una locación residencial de tipo doméstico familiar: Uchuquita 1, 2 y 3, permitiéndonos ubicarla en el primer componente temporal y sostener la configuración de dos paisajes sociales durante el período Formativo local.

El paisaje aldeano comunitario de la cuenca de Anillaco

\section{Antecedentes}

Las investigaciones realizadas en el Departamento de Castro Barros (Agua Blanca, Los Molinos, Anillaco, Chuquis y Pinchas) indicaron una intensa presencia en el piedemonte oriental de comunidades productoras durante el primer milenio D.C. Se identificaron sitios arqueológicos como unidades residenciales dispersas cercanas a terrazas de cultivo y sectores de molienda (Cahiza 2015; Callegari et al. 2015; Duglosz et al. 2009; Mercado 1993; Raviña y Callegari 1998). 
Particularmente en Anillaco se han identificado locaciones como Faldeos de Anillaco I, II, III, 28, 31 y 39 y Quebrada de Anillaco. Estos sitios están compuestos por recintos de dimensiones techables asociados a sectores de mayor tamaño denominados "patios" (Raviña y Callegari 1992). Entre los sitios residenciales se presentan terrazas de cultivo perpendiculares a las laderas construidas con técnica de muro simple y áreas de molienda (Callegari et al. 2015).

Las dataciones radiocarbónicas realizadas en Anillaco como así también en otros sitios ubicados en las cuencas de Anjullón y Los Molinos presentan una alta coherencia de sitios multiresidenciales que oscilan entre los 600800 DC. En cuanto al registro cerámico, en todos los casos predominan las tradiciones estilísticas que podrían asignarse a conjuntos Allpatauca, Ciénaga y Aguada (Cahiza 2015; Mercado 1993; Raviña y Callegari 1992).

\section{Metodología}

El área de estudio abarca por un lado la quebrada y faldeos de la cuenca de Anillaco ( $28^{\circ} 50^{\prime} \mathrm{S} / 66^{\circ} 56^{\prime} \mathrm{O}$ ) que se encuentran surcados por cauces permanentes y temporales. Por otro lado, la zona de la depresión con el río La Punta como colector intermitente de los cauces del piedemonte que descienden de la Sierra del Velasco.

Desarrollamos un modelo de prospección intensiva de cobertura total abarcando $90 \mathrm{~km}^{2}$ con un gradiente de altitud desde 1200 a 1800 msnm. Para ello delimitamos 12 parches relacionados a marcadores naturales y antrópicos como arroyos, acequias y parcelas de cultivo modernas. Estas demarcaciones fueron georreferenciadas en Google Earth permitiendo crear un mapa de prospección.

Asimismo, se llevaron a cabo recolecciones superficiales controladas, localización y relevamiento de estructuras residenciales, productivas y de molienda. Estos datos fueron registrados en cartografías, planillas, GPS y relevamientos planimétricos.

La agregación o segregación de las localizaciones fueron procesadas mediante el uso de paquetes estadísticos y Sistemas de Información Geográfica -ArcGIS 10.1-. Esta herramienta nos permitió gestionar la información obtenida en el campo y trasformar la distribución de puntos en una reconstrucción de las sociedades que habitaron la cuenca del río Anillaco.

Por último aplicamos el análisis Multiple Ring Buffer el cual a partir de la trasformación de los datos puntuales (áreas de cultivo) en múltiples polígonos circulares (Buffer) de 100 a 500m de radio y la incorporación de sectores residenciales y de molienda permite conocer el área de influencia y proximidad espacial entre estas entidades.

Resultados

El registro material y su distribución

Los datos relevados manifestaron la presencia de 112 locaciones arqueológicas identificadas como sitios

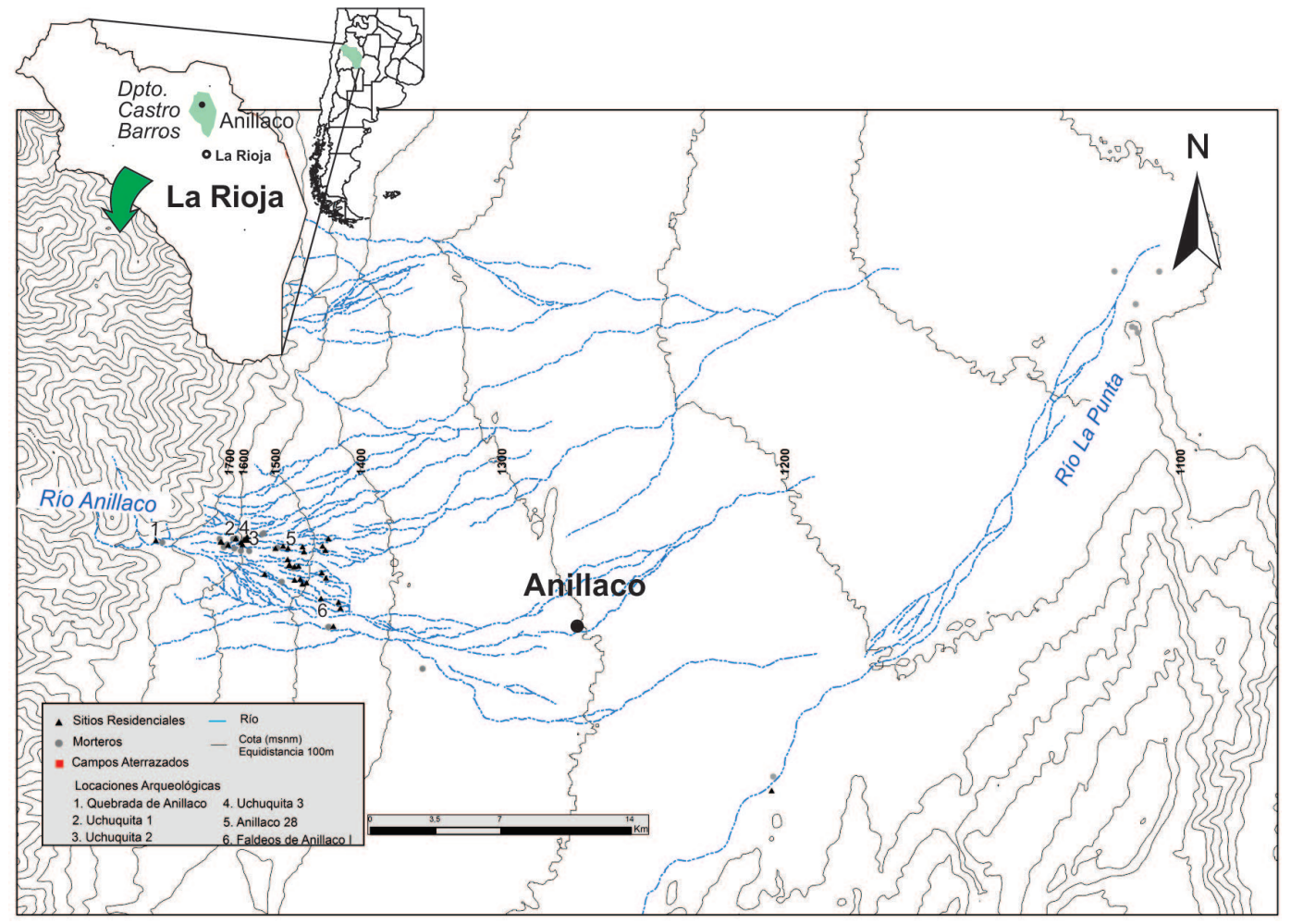

Figura 1. Distribución de sitios residenciales, morteros y campos aterrazados.

Figure 1. Location of residential sites, mortars and terraced fields. 
residenciales con arquitectura de piedra $(n=36)$, terrazas de cultivo ( $n=31)$ y morteros fijos $(n=45)$ (Figura 1$)$.

Los conjuntos habitacionales son de tamaño reducido (20 y $25 \mathrm{~m}^{2}$ ) y la altura actual de las paredes oscilan entre los 50 a $60 \mathrm{~cm}$. La altura estimada a partir de la excavación y del volumen de los derrumbes indicaría una altura aproximada de $2 \mathrm{~m}$. En cuanto a las edificaciones de mayores dimensiones como los "patios" presentan superficies entre 30 y $270 \mathrm{~m}^{2}$ con paredes de $30 \mathrm{~cm}$ a $1 \mathrm{~m}$ de alto.

La técnica constructiva empleada se caracteriza por grandes bloques de piedra verticales de cimiento, con bloques más pequeños encima de los mismos. Los muros son dobles o simples, sin argamasa y en algunos casos se presentan refinados como en Faldeos de Anillaco I y Anillaco 28. En general, las edificaciones habitacionales son cuadrangulares, rectangulares y subrectangulares, mientras que los patios tienen forma trapezoidal y cuadrangular (Callegari et al. 2015).

A partir de la variabilidad arquitectónica -superficie, cantidad de recintos y técnica constructiva- y siguiendo a Cahiza (2015), categorizamos las locaciones como:

1. Recintos simples $(n=14)$ : presentan uno o dos recintos habitacionales. 2. Recintos simples en terrazas de cultivo $(n=7)$ : recintos techables emplazados en áreas de cultivos aterrazadas. 3. Recintos compuestos $(n=7)$ : presentan varios recintos habitacionales asociados a uno o más espacios abiertos o patios (Uchuquita 1). 4. Recintos compuestos en terrazas de cultivo $(n=7)$ : presenta recintos techables junto a dos o más patios emplazados en áreas de cultivos aterrazadas (Anillaco 28 y Quebrada de Anillaco). 5. Recintos complejos $(n=1)$ : combinaciones de recintos habitacionales, patios y espacios públicos -plataformas y montículo- (Faldeos de Anillaco I).

A partir de la localización de los sitios residenciales categorizados como simples y simples en terrazas de cultivo se emplazan en el piedemonte entre $1400 \mathrm{y}$ 1600 msnm, tanto del sector $\mathrm{N}$ como S. Las locaciones compuestas y complejas se ubican en su mayor parte en el sector SE de la cuenca del río Anillaco y a una altitud similar entre 1450 y 1550 msnm.

Nuestros análisis muestran una configuración aldeana que se concentra en los faldeos de la sierra ubicada al SE del cono aluvional y de acuerdo a las categorías constructivas anteriormente mencionadas pudimos identificar unidades constructivas de recintos compuestos,

Tabla 1. Frecuencia y superficie de las categorías arquitectónicas.

Table 1. Frequency and surface of each architecture categorie. recintos compuestos con terrazas de cultivo y recintos complejo que incluye el montículo del conjunto Faldeos de Anillaco I y Anillaco 28.

En relación con las frecuencias y superficies de los conjuntos residenciales, la categoría de Recintos compuestos y complejos es la que posee menor representatividad, aunque el total de su superficie es mayor a la de los recintos simples (Tabla 1).

De este modo, observamos una dinámica ocupacional marcada por un uso continuo del espacio cuya evidencia más notoria es la existencia de distintas unidades residenciales de tamaños pequeños -domésticos- y grandes -domésticos/congregación comunal- que podrían reflejar una organización sociopolítica y económica basada en jerarquías comunitarias de baja escala.

Los espacios productivos se ubican en el SE del cono aluvial en áreas cercanas e intercaladas con los espacios residenciales y de molienda. Las terrazas de cultivo están compuestas por piedras erigidas de hilera simple separadas por dos a tres metros de distancia una de otra, perpendiculares a la pendiente y a los cauces naturales. Estos lineamientos están emplazados en sectores levemente elevados sin encauzamiento artificial del agua.

Pudimos determinar superficies que abarcan entre $170 \mathrm{y}$ $28.000 \mathrm{~m}^{2}$ totalizando $40.919 \mathrm{~m}^{2}$. La escasa superficie, planificación y distancia respecto a los sitios residenciales nos llevan a proponer una producción de alimentos de tipo familiar.

El análisis de Buffer demostró, que en la mayoría de los casos residenciales y áreas de molienda, a partir de áreas de radio de entre 100 y $200 \mathrm{~m}$ se encuentra uno o varios espacios de cultivo. Con lo cual queda en evidencia la cercanía entre sitios residenciales, áreas de molienda y sectores productivos y la ausencia de una planificación que signifique la asignación de espacios exclusivos para la residencia, práctica agrícola y procesamiento de alimentos aunque el sector SE del cono aluvional presenta cierta recurrencia de locaciones productivas (Figura 2).

Se identificaron 45 locaciones de morteros fijos que poseían entre 1 a 10 bocas, registrando un total de

\begin{tabular}{lcrl}
\hline \multicolumn{3}{c}{ Categorización de locaciones residenciales en Anillaco } \\
Categorías & $\mathrm{n}$ & Superficie total $\left(\mathrm{m}^{2}\right)$ \\
\hline $\begin{array}{l}\text { Recintos simples } \\
\text { Recintos simples en }\end{array}$ & $17(47 \%)$ & 280,834 & $(4 \%)$ \\
terrazas de cultivo & $7(19 \%)$ & 210,89 & $(3 \%)$ \\
Recintos compuestos & $7(19 \%)$ & 2789,98 & $(42 \%)$ \\
Recintos compuestos en & & & \\
terrazas de cultivo & $7(19 \%)$ & 2771,85 & $(42 \%)$ \\
Recintos complejos & $1(3 \%)$ & 613,38 & $(9 \%)$ \\
Total & $36(100 \%)$ & 6666,934 & $(100 \%)$ \\
\hline
\end{tabular}




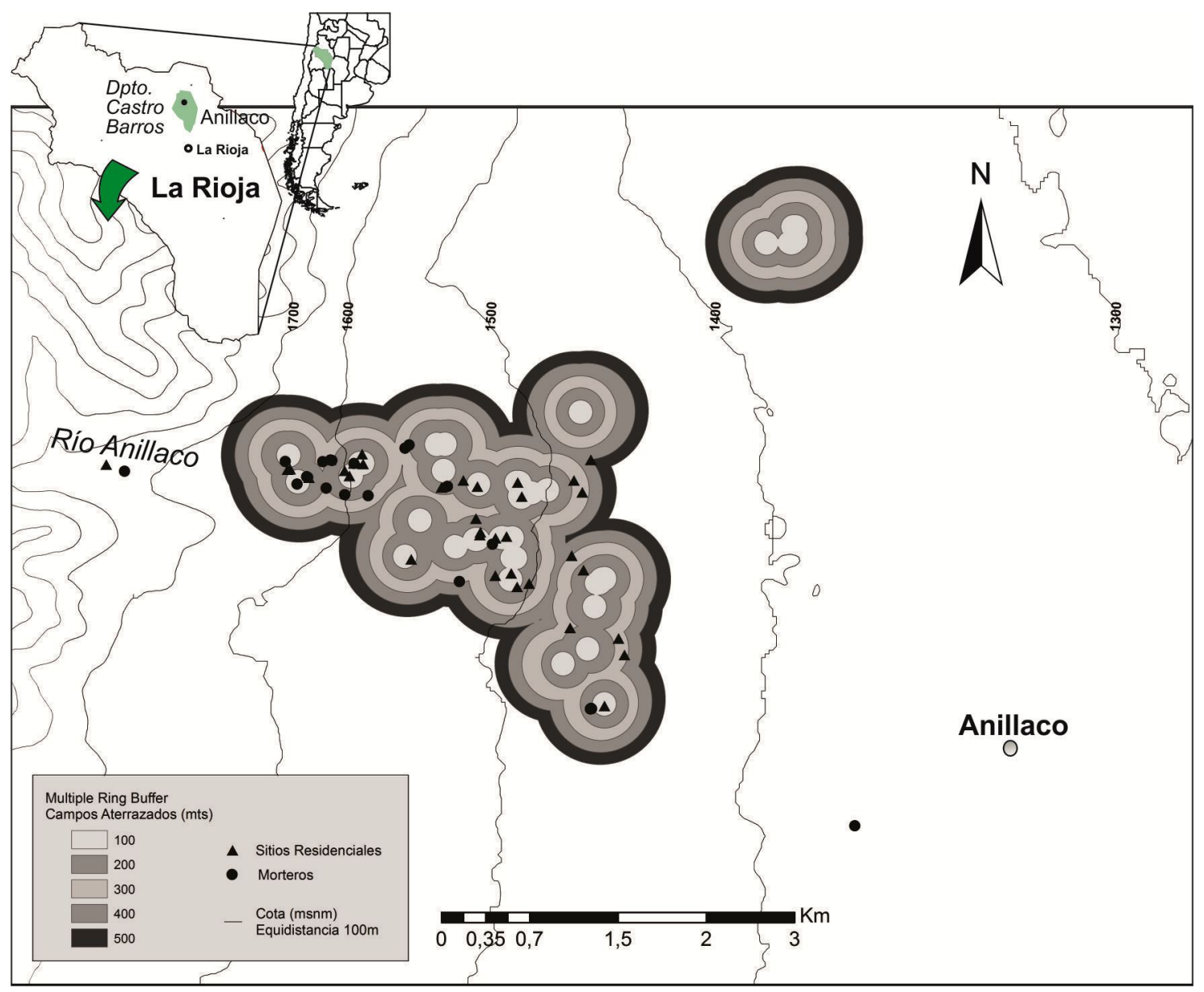

Figura 2. Distribución de sitios residenciales, morteros y áreas de Múltiple Buffer Ring de sectores productivos.

Figure 2. Distribution of residential sites, mortars and Múltiple Buffer Ring of sector productive

116 bocas. Sin embargo, no se han encontrado hasta el momento manos de moler. La mayor frecuencia de morteros se localizó en el sector del piedemonte y próximos a los sitios residenciales y espacios productivos, en la cercanías de los cauces inactivos y activos en donde se encuentra unas de las áreas de concentración de recursos forestales. En cambio, en las márgenes del río de La Punta la frecuencia de morteros hallados es menor y asociados también a sectores de bosques. Estos podrían haberse utilizado para el procesamiento de alimentos de origen silvestre (como por ejemplo, Prosopis spp.) o domesticado (Zea mays).

\section{Conjuntos de escala doméstica: Uchuquita 1, 2 y 3}

Nuestros trabajos actuales también están dirigidos a definir las características, la estructuración y el uso del espacio residencial de escala familiar que habitó la cuenca de Anillaco. Seleccionamos Uchuquita' para

\footnotetext{
${ }^{1}$ Ají Uchuquita (Capsicum chacöense Hunz) arbusto de la familia Solanaceae que crece a la vera de los cauces secos de la Sierra del Velasco. Su fruto al ser picante fue utilizado por los antiguos pobladores como preservante de alimentos, actualmente es usado en las comidas (Aranda Rickert 2014).
}

ser intervenido con excavaciones, por ser un conjunto arquitectónico residencial de escala doméstica. Se localiza en una loma longitudinal emplazada entre dos cauces transitorios temporales. El sitio está integrado por tres sectores residenciales-Uchuquita 1, 2 y 3 -compuestos por patios y habitaciones de muro de piedra con planta semicircular y semirectangular (Figura 3).

Los mapeos planímetros y microtopográficos detallados (realizados con teodolito) identificaron a Uchuquita 1 como una locación de $230 \mathrm{~m}^{2}$ con ocho estructuras subcuadrangulares, dos de las cuales son recintos de dimensiones techables intercalados entre seis espacios abiertos de dimensiones mayores. En la pared $\mathrm{N}$ de uno de los espacios abiertos se localiza un mortero fijo.

Hacia el E de Uchiquita 1 y a $17 \mathrm{~m}$ de distancia pendiente abajo, se ubica Uchuquita 2, constituido por dos recintos aislados entre sí con una planta cuadrangular de $28 \mathrm{~m}^{2}$.

Por último, hacia el $\mathrm{N}$ cruzando un cauce temporal del río Anillaco se encuentra Uchuquita 3, con tres estructuras habitacionales cerradas y dos estructuras abiertas adosadas a un muro perimetral de $12 \mathrm{~m}$ de extensión. 


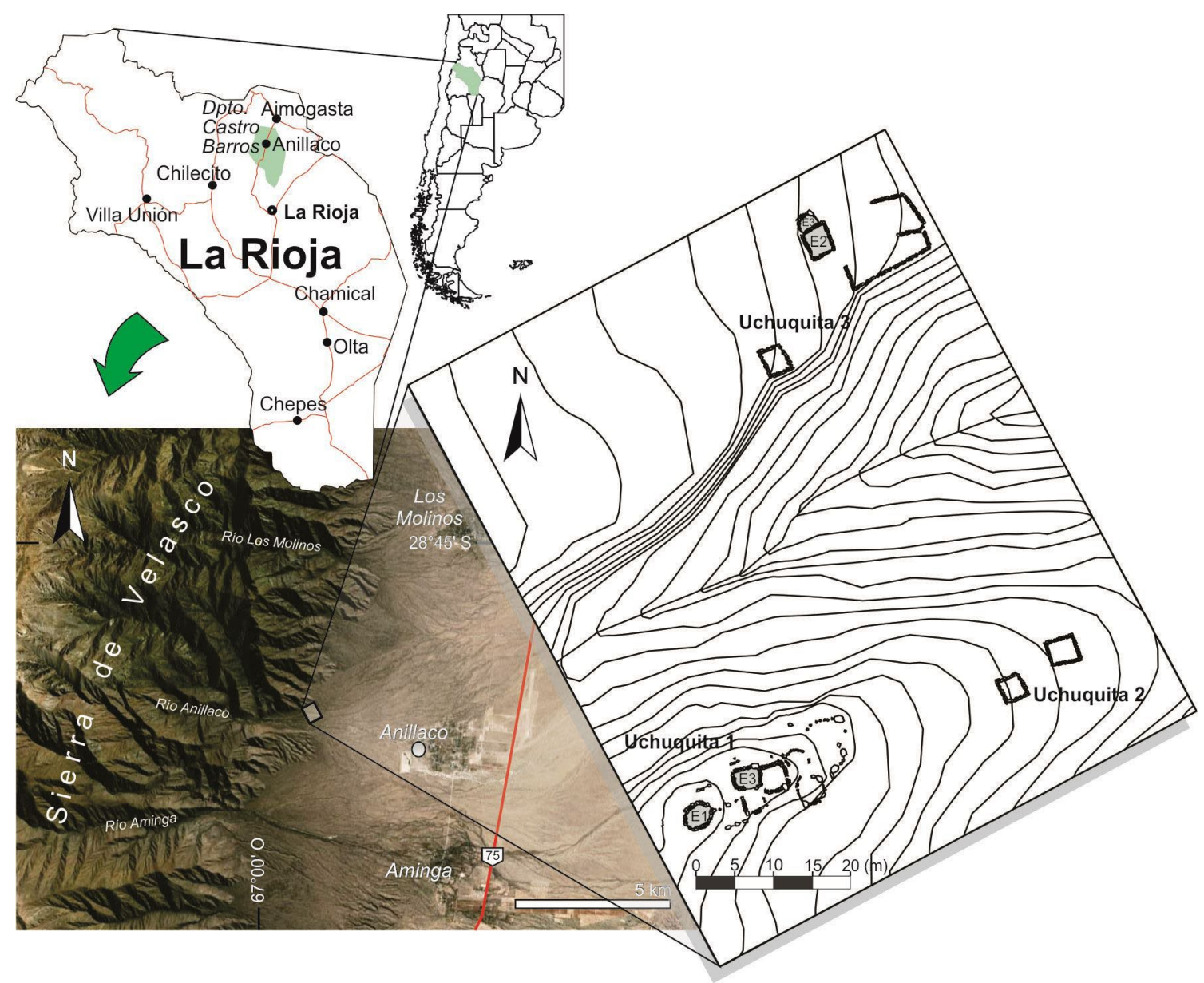

Figura 3. Plano topográfico de los conjuntos residenciales Uchuquita 1, 2 y 3.

Figure 3. Topographic map of the residential complexes Uchuquita 1, 2 and 3.

Este conjunto tiene una superficie de $220 \mathrm{~m}^{2}$.

La técnica constructiva empleada en Uchuquita es similar a la ya registrada por otros investigadores en Anillaco (Raviña y Callegari 1992), tales como los registrados en Anjullón (Mercado 1994), Chuquis (Duglosz et al.2009) y Los Molinos (Cahiza 2015). En las excavaciones recientes realizadas en Uchuquita 1 (E1 y E3) y Uchuquita 3 (E2 y E3) se ha registrado paredes robustas de 50 a $60 \mathrm{~cm}$ de ancho, de doble hilera y muros de arranque compuesto por bloques de $80 \mathrm{~cm}$ de alto y $60 \mathrm{~cm}$ de ancho colocados en forma vertical.

Se identificó en Uchuqita 3 (E3) un componente ocupacional entre 40 y $50 \mathrm{~cm}$ de profundidad que fue datado en $1760+/-50$ años AP (LP-3259-carbón vegetal) ca. 250 a 370 D.C. El registro estaba caracterizado por la presencia de cerámicas asociadas a los componentes tradicionalmente denominados Ciénaga y Aguada y el conjunto óseo demostró una preferencia por el consumo de camélidos².

\footnotetext{
${ }^{2}$ Los análisis óseos fueron realizados por Enrique Garate y Jorge García Llorca y son parte de un trabajo específico en preparación.
}

\section{Discusión y conclusiones preliminares}

Entre el 300 y el 800 DC las sociedades aldeanas del norte de la Rioja desarrollaron diferentes estrategias de aprovechamiento y transformación del espacio natural (principalmente los recursos de agua y suelo) con la construcción de espacios residenciales y productivos resultando diferentes paisajes sociales.

En este proceso, distinguimos dos temporalidades del paisaje de Anillaco, por un lado los sitios que podrían corresponder a un primer componente temprano ubicado entre los 300 y 600 D.C. Entre estas locaciones se encuentra Uchuquita 1, 2 y 3.

Un caso similar se presenta en la cuenca de Los Molinos (Departamento de Castro Barros), denominada Terraza 5 compuesto por terrazas de cultivo asociado a dos habitaciones residenciales datado entre los ca. 300 a 500 D.C (Cahiza 2015). Estas locaciones son ejemplos de sitios residenciales simples y compuestos, articulaciones de pequeñas unidades habitacionales y patios que por sus dimensiones y cantidades de espacios podrían corresponderse con unidades del 
tipo doméstico familiar. En general predomina la construcción con paredes de piedra en hilada simple o doble, de morfología cuadrangular/rectangular e incluso trapezoidal con espacios abiertos. Estas características nos impulsan a proponer no sólo la contemporaneidad de estas locaciones residenciales sino también que esta arquitectura doméstica se relacionarían con un primer componente temporal durante el Formativo local.

Por otro lado, a las locaciones del segundo componente datados temporalmente entre ca. 600-800 D.C (Faldeos de Anillaco I, Anillaco 28 y Quebrada de Anillaco) (Raviña y Callegari 1991) se las ha categorizado como sitios compuestos entre terrazas de cultivo y complejos ya que presentan espacios residenciales concentrados y arquitectura pública/ritualizada.

En estos sitios la distribución concentrada de espacios residenciales se relaciona con algunos de los aspectos centrales de la definición de comunidad: la co-residencia, que en ámbitos de los conjuntos residenciales como Faldeos de Anillaco I alcanzó niveles más intensos. De esta manera, podríamos estar frente a una unidad social comunitaria con una integración local que construyó espacios de uso simbólico.

Más allá de la variabilidad arquitectónica observamos una recurrencia en las técnicas constructivas tanto de las locaciones residenciales como las productivas. Esto nos lleva a plantear que las comunidades aldeanas de Anillaco compartieron tareas articuladas de la vida diaria reflejando una transmisión y continuidad de las prácticas sociales. Estas formas de hacer de uso común reflejarían identidades grupales y elecciones compartidas en la configuración de los paisajes sociales de Anillaco.

\section{Agradecimientos}

A Pablo Cahiza y Adriana Aranda Rickert por su dirección, formación y acompañamiento. A nuestros compañeros Soledad Gheggi, Silvina Rodríguez, Agustina Acevedo, Enrique Garate, Gonzalo García, Belén Olmedo, Sebastián, Candela, Gerónimo y Felix Fracchia, María José Cavallo y
José Paliza, Sebastián Rocher y Marcos Machioli, quienes colaboraron en los trabajos de campo y de laboratorio.

\section{Bibliografía}

Aranda Rickert, A. 2013. Flora del parque geológico Sanagasta. Serie Ciencias Naturales CRILAR: 43, La Rioja.

Cahiza, P. 2015.Un acercamiento espacial a los paisajes comunitarios formativos de Los Molinos, Castro Barros, La Rioja. Relaciones de la Sociedad Argentina de Antropología XL (1): 101-122

Callegari, A.; M. E. Gonaldi; G. Spengler; M. E. Aciar; M. G. Rodríguez; R. Pappalardo \& M. L. Wisnieski. 2015. Tras las Huellas del Formativo. Norte de la Provincia de La Rioja. Editores M. A. Korstanje, y M. Lazzarri. Editores asociados M. Basile, F. Bugliani, V. Lema, L. Pereyra Domingorena y M. Quesada. Crónicas materiales precolombinas. Arqueología de los primeros poblados del NOA, 1: 1247275, Sociedad Argentina de Antropología, Buenos Aires.

Dlugosz, J. C., M. S. Gianfrancisco; A. Richard, F., Villar \& Núñez Regueiro, V. A. 2009. Arqueología del Sitio El Puesto (Dpto. Castro Barros, La Rioja). Andes, 20:135-160, Universidad Nacional de Salta, Argentina.

Mercado, G. 1993. El yacimiento arqueológico de Anjullón. Investigación Preliminar. Anales de Arqueología y Etnología. Universidad Nacional de Cuyo, Mendoza.

Raviña, M. \& Callegari, A. 1988. Mapa arqueológico de la provincia de La Rioja. Revista del Museo de La Plata, 67: 21-92.

Raviña, G. \& Callegari, A. 1991. Espacio de asentamiento y sistema de sitios en el departamento Castro Barros, La Rioja". Revista de El Shincal, 3: 47-53.

Raviña, G \& A, Callegari. 1992. "La Presencia Aguada en el departamento de Castro Barro (La Rioja)". Palimpsesto. Revista de Arqueología, 1: 50-70. 